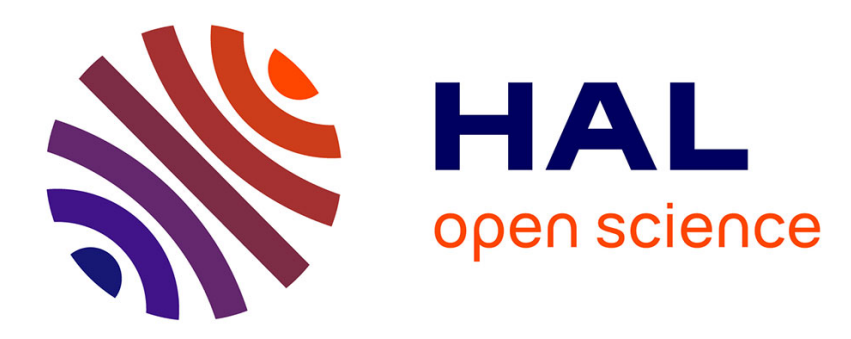

\title{
Premeiotic microsporocyte cell shape influences shape of tetrads during microsporogenesis
}

\author{
Laurent Penet
}

\section{To cite this version:}

Laurent Penet. Premeiotic microsporocyte cell shape influences shape of tetrads during microsporogenesis. International Journal of Plant Sciences, 2012, 173 (4), pp.375-381. 10.1086/664716 . hal02646375

\section{HAL Id: hal-02646375 \\ https://hal.inrae.fr/hal-02646375}

Submitted on 29 May 2020

HAL is a multi-disciplinary open access archive for the deposit and dissemination of scientific research documents, whether they are published or not. The documents may come from teaching and research institutions in France or abroad, or from public or private research centers.
L'archive ouverte pluridisciplinaire HAL, est destinée au dépôt et à la diffusion de documents scientifiques de niveau recherche, publiés ou non, émanant des établissements d'enseignement et de recherche français ou étrangers, des laboratoires publics ou privés. 
Int. J. Plant Sci. 173(4):375-381. 2012.

(C) 2012 by The University of Chicago. All rights reserved.

1058-5893/2012/17304-0004\$15.00 DOI: $10.1086 / 664716$

\title{
PREMEIOTIC MICROSPOROCYTE CELL SHAPE INFLUENCES SHAPE OF TETRADS DURING MICROSPOROGENESIS
}

\author{
Laurent Penet ${ }^{1, *}$ \\ *Ecologie, Systématique et Evolution, Unité Mixte de Recherche (UMR) 8079, Bâtiment 360, Université Paris-Sud, F-91405 Orsay cedex, France; \\ and UMR 8079, Bâtiment 360, Centre National de la Recherche Scientifique, F-91405 Orsay cedex, France
}

\begin{abstract}
Angiosperm microspores are grouped into tetrads before they mature into functional pollen grains. This tetrad stage is an important step in microsporogenesis. Tetrad shapes are diverse across angiosperms, with high levels of variation sometimes occurring within species, reflecting variation in early developmental events of nuclear and cell division (i.e., meiosis and cytokinesis). Among these developmental influences, the shape of the microsporocyte (pollen mother cell; hereafter PMC) is likely to influence tetrad shape. This article presents a test of this hypothesis in 19 species of higher Asparagales with a successive cytokinesis by inferring PMC shape from tetrads observed with epifluorescence microscopy. Sampled species show differences in PMC shape between groups of regular or irregular tetrads at the species level, and there is a strong component of PMC shape variation at the onset of meiosis on resulting tetrad shape, with more elongated PMCs yielding significantly more irregular tetrads.
\end{abstract}

Keywords: Asparagales, cell shape, microsporogenesis, pollen mother cell, tetrad.

\section{Introduction}

Pollen grains are vital components of plants' life cycles (Blackmore 2007) because they govern male function and are a key factor of reproductive success (Furness and Rudall 2004). At the molecular level, many studies have investigated specific pollen genes and proteins and are beginning to unveil the details of cell structure, organization, and patterning during pollen development (Wilson and Zhang 2009; Ma and Sundaresan 2010; Grossniklaus 2011). Also, the description of key features of pollen development (i.e., microsporogenesis) revealed the connection between pollen grain development diversity and the resulting phenotypic diversity (e.g., size, shape, ornamentation, and specialized pollen germination structures such as apertures; Ressayre et al. 2002; Albert et al. 2009, 2011a). Furthermore, it has been shown that pollen diversity may functionally relate to the ecology of pollination (Hesse 2000; Sannier et al. 2009).

Microsporogenesis is a relatively straightforward developmental process that involves only a few key steps before mature pollen is produced (i.e., meiosis typically followed by one or two mitotic divisions). Microsporogenesis is initiated in microsporocytes (also called pollen mother cells; hereafter referred to as PMCs), which are diploid cells undergoing meiosis to form a tetrad of microspores. An important callose deposit constrains the shape of the PMC (Angold 1967; Abramova et al. 2003). Each further microsporogenesis step is then characterized by great developmental diversity (Furness et al. 2002). First, cytokinesis, the physical division into separate

\section{${ }^{1}$ E-mail: laurent.penet@gmail.com.}

Manuscript received October 2011; revised manuscript received November 2011. cells, may occur at different stages of nuclear meiotic divisions, leading to successive, simultaneous, or even intermediate or unusual types of cytokinesis (Sampson 1969; Caddick et al. 1998; Ghimire et al. 2011). Second, cell wall formation can be achieved centripetally or centrifugally (Ressayre et al. 2005 ) or even both ways (Penet et al. 2005), and it plays a key role during pollen development (Albert et al. 2010). Third, postmeiotic sister cells are grouped into tetrads with a dramatic diversity of shapes (Penet et al. 2007) that may stay cohesive until anther dehiscence and pollen dispersal (Copenhaver 2005). Fourth, aperture number and exine ornamentation of pollen grains vary dramatically within and among plant families or even at lower taxonomic levels (Nadot et al. 2008). Finally, mitoses leading to mature pollen grains with differentiated vegetative and sperm nuclei may be postponed to various degrees following the young microspore stage (Brewbaker 1967).

Tetrad shape is a character of long-standing interest in studies of microsporogenesis and systematics, especially because of its strong association with cytokinesis type (Nadot et al. 2006, 2008). Indeed, a successive cytokinesis (by which cell division occurs between each meiotic nuclear division) usually produces tetragonal and decussate tetrad shapes (Rangaswamy et al. 2001), while simultaneous cytokinesis (whereby cell division occurs after meiotic nuclear division is fully completed) results mostly in tetrahedral tetrad shape and more rarely in rhomboidal shape (Rudall et al. 1997). Other irregular tetrad shapes may also be produced in plants, especially in species with a successive cytokinesis. Irregular tetrad shapes usually occur at very low frequencies and at times were considered teratological. However, in some species, irregular tetrad shapes can be produced at somewhat higher rates or even become the majority (Penet et al. 2005; Albert et al. 2011b). I further investigated whether tetrad shape regularity could be explained 

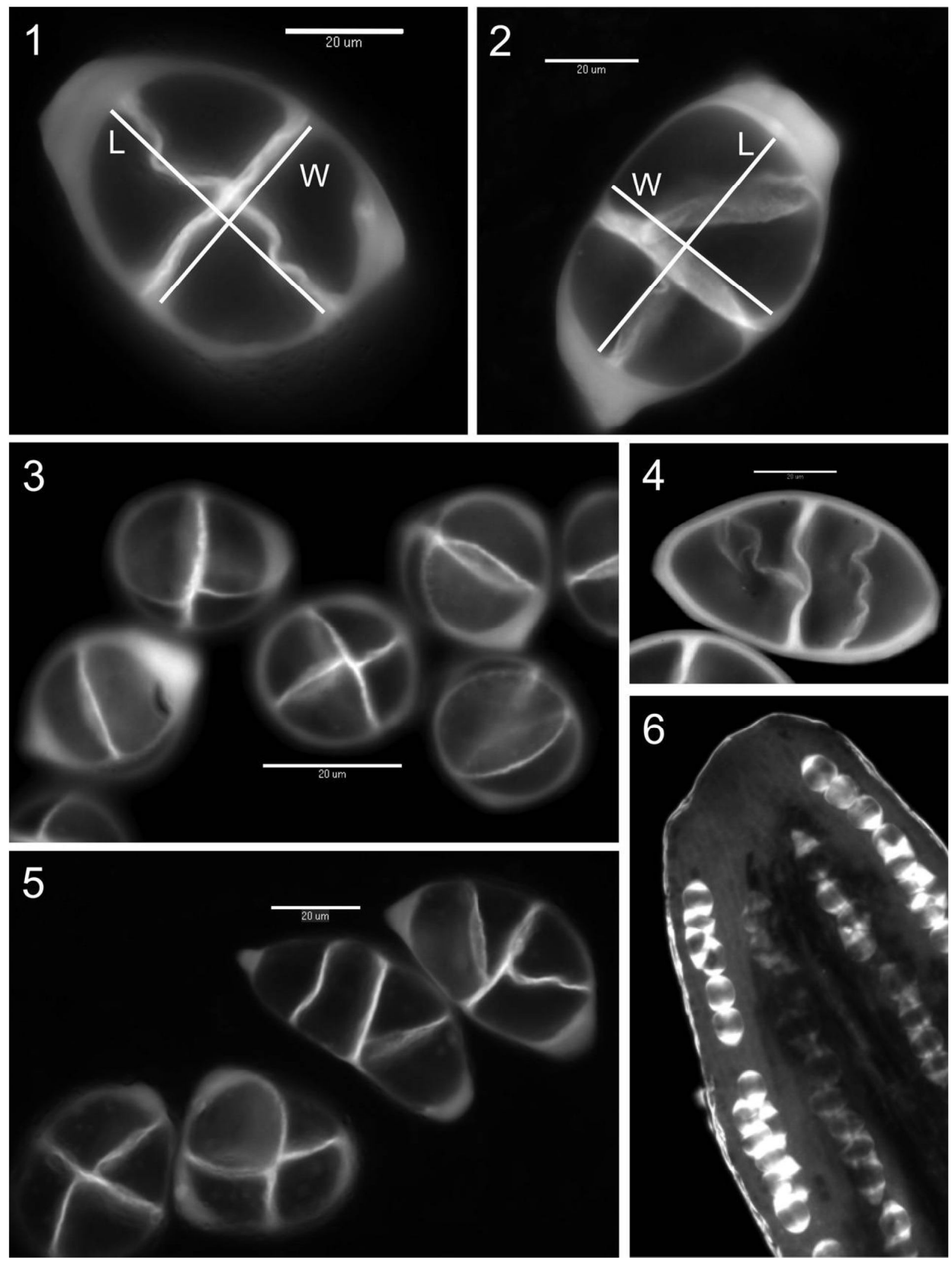

Fig. 1 Tetrads stained with aniline blue. Figs. 1.1, 1.2, Tetrads from Hosta sp. (tetragonal tetrad with regular shape and irregular decussate tetrad with irregular shape, respectively). Fig. 1.3, Population of tetragonal (regular) tetrads from Hypoxidia maheensis. Fig. 1.4, T-shaped (irregular) tetrad from Albucca nelsonii. Fig. 1.5, Regular and irregular tetrads from Moraea aristata. Fig. 1.6, Anther of Agapanthus praecox with microsporocytes filling the locular space. Measures recorded on tetrads are illustrated in figs. 1.1 and $1.2(\mathrm{~L}=$ length; W $=$ width). Scale bars represent $20 \mu \mathrm{m}$. 
by specific developmental features, specifically, whether they had a link with the PMC shape.

I tested this developmental hypothesis in Asparagales (Angiosperm Phylogeny Group 1998, 2003), a clade of plant species that is characterized by an apomorphic successive cytokinesis and exhibits diversity in tetrad shape (Rudall et al. 1997; Furness and Rudall 1999, 2001). In this study, I specifically address these questions: (1) To what extent do PMC shapes differ among species? and (2) Do tetrad shape groups (regular vs. irregular) originate from different PMC shapes? The results show that few species produce PMCs with a high diversity of shapes and that premeiotic PMC shape does have an impact on resulting tetrad shape.

\section{Material and Methods}

The influence of PMC shape on tetrad shape during microsporogenesis was investigated in 19 species belonging to eight families from Asparagales (Angiosperm Phylogeny Group 2003): family Hypoxidaceae: Hypoxidia mabeensis Friedmann; Iridaceae: Moraea aristata (Houtt.) Asch. \& Graebn.; Alliaceae: Allium altaicum Pall., Allium ursinum L.; Amaryllidaceae: Narcissus poeticus L., Agapanthus umbellatus L'Hér.; Themidaceae: Triteleia ixioides ssp. scabra Greene; Hyacinthaccac: Albuca nelsonii N.E.Br., Eucomis autumnalis (Mill.) Chittenden, Hyacinthus non-scriptus L., Ornithogalum longebracteatum Jacq., Veltheimia bracteata Harv. ex Baker; Agavaceae: Yucca agavoides Horl. ex Carr., Arthropo- dium cirrhatum G. Benn., Beschorneria yuccoides K.Koch, Chlorophytum pauciflorum Dammer, Hosta sp.; Convallariaceae: Polygonatum multiflorum Kunth, Convallaria majalis L. Voucher references are available in Penet et al. (2005).

For each species, I squashed anthers from several young buds in aniline blue and performed observations under epifluorescence microscopy (Nadot et al. 2006). Aniline blue specifically stains callose and allows observations of the callose wall surrounding PMCs and young tetrads before the wall disappears before microspore release (Angold 1967). Very early shapes for sporogenous cells, before they reach the stage of premeiotic microsporocytes, are usually isodiametric (Furness 2008) or even already very elongated in some species (e.g., in Asclepiadoideae; dan Dicko-Zafimahova 1980), and shape may vary from early sporogenous cells to premeiotic microsporocytes. Nevertheless, once callose deposition is thick enough, changes in cell shape are much less dramatic. The callose deposit is continuous and mostly even, thus keeping a similar length to width ratio between the premeiotic PMC stage (just before meiosis and cytokinesis are initiated) and young tetrad stage (just after meiosis and cytokinesis are completed). In fact, when I compared the length : width ratio at both stages in a species with mostly regular tetrads (Agapanthus praecox) and another with mostly irregular tetrads (A. nelsonii), ratios did not differ between premeiotic PMC and young tetrad stages (Welch $t$-test for uncqual variances, $t=-0.87, P=0.39, n=60$, and $t=0.40, P=0.69, n=60$, respectively).

In this study, I therefore used the tetrad length: width ratio (figs. 1.1, 1.2) as a proxy for premeiotic PMC shape. The clas-

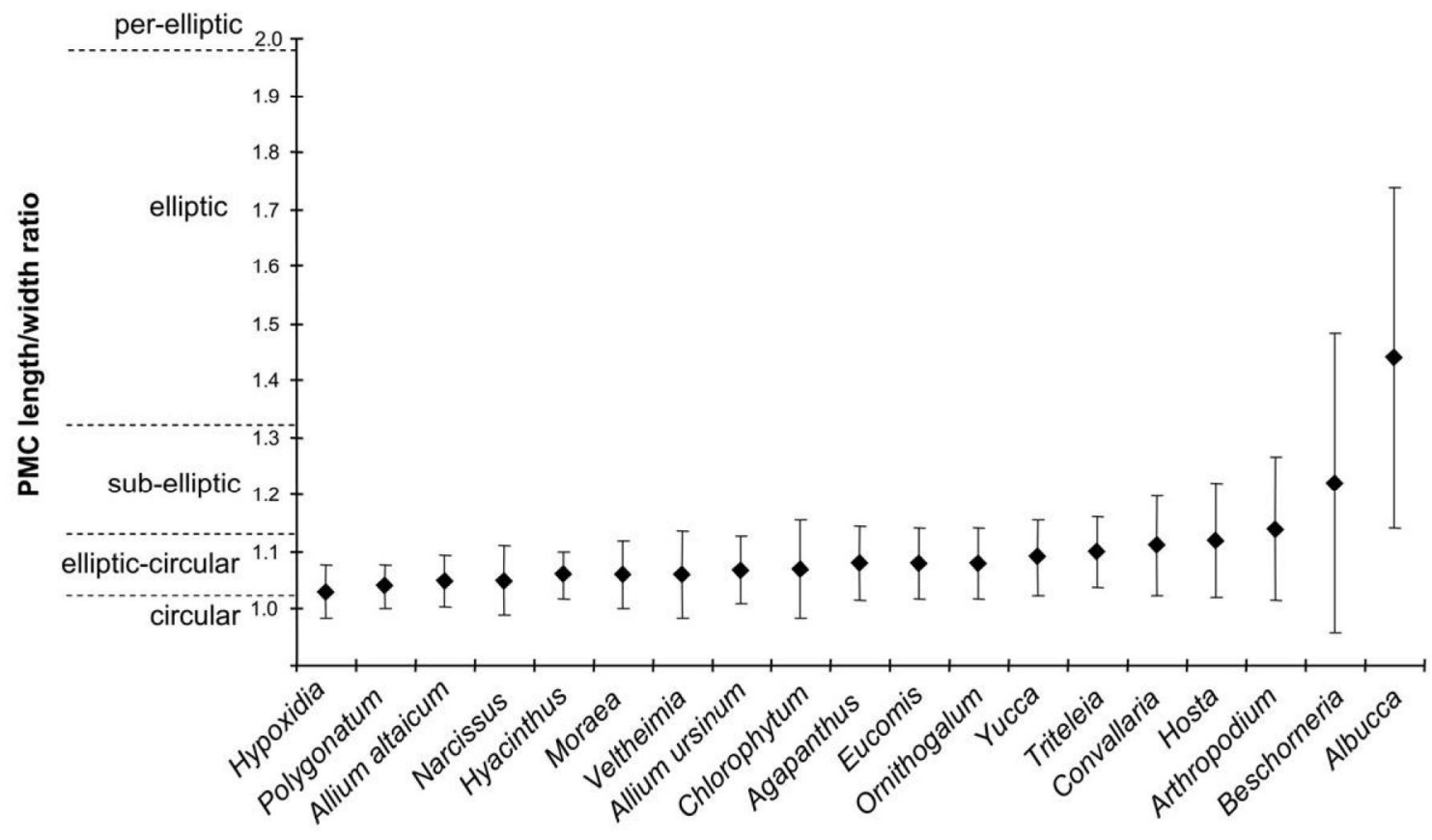

Study species

Fig. 2 Mean ( $\perp$ SD) pollen nother cell (PMC) length: width ratio and corresponding shapes in the 19 study species of Asparagales. Study species are indicated by their genus name, except for Allium congenerics. Species are ranked from lowest to highest average PMC length: width ratio. 
sification suggested by Erdtman for pollen grains was followed (Erdtman 1969, cited in Harley and Dransfield 2003). According to the ratio value, PMC shape falls into one of five classes: circular $($ ratio $=1.00)$, elliptic-circular $(1.01-1.13)$, subelliptic (1.14-1.32), elliptic (1.33-2.00), and per-elliptic $(>2.00)$, the latter being very rare. I measured the length and width (in $\mu \mathrm{m})$, excluding the callose deposit, of 30-60 tetrads per species ( $n=643$ tetrad observations). The shape of each measured tetrad was also recorded. Tetrad shapes were then classified into two groups: regular (i.e., tetragonal and decussate; see figs. 1.1, 1.3, 1.5) or irregular (linear tetrads, which are rare [fig. 1.5] and intermediate ones, such as T-shaped [figs. 1.2, 1.4, 1.5]).

For the six species where at least five irregular tetrads were found, I tested whether the regular tetrad group differed from the irregular group in their mean PMC length: width ratio, using Welch $t$-tests for unequal variances in $\mathrm{R}$ ( $\mathrm{R}$ Development Core Team 2011). A G-test of independence across all 19 species was conducted to investigate the relationship between PMC shapes and tetrad shapes (regular vs. irregular groups). Because of sampling limitations with per-elliptic PMC shape, elliptic and perelliptic shapes were pooled to fit the requirements of the test.

\section{Results}

PMC shapes were variable among the 19 study species of Asparagales (fig. 2). In most species, this variation resulted in average circular to elliptic-circular PMCs, but a few species also produced subelliptic PMCs. Average subelliptic PMCs were found in Convallaria majalis, Hosta sp., Arthropodium cirrhatum, and Beschorneria yuccoides, and only Albucca nelsonii produced mainly elliptic PMCs (fig. 2). In the latter two species, PMCs spanned the full range of shapes and varied from circular to elliptic.

As for tetrad shape (see examples in fig. 1), I found irregular tetrads in 10 of the study species (table 1), with A. nelsonii and B. yuccoides the only ones presenting irregular tetrads with a linear shape (fig. 1.4). When plotting tetrad shapes according to length and width measures corresponding to PMCs for these two species, linear and regular tetrads segregate distinctly, whereas tetrads of intermediate shape span along the species PMC size range (fig. 3). This distribution was not observed in the other species with lower variation in PMC shape (data not shown).

Overall, I found a larger mean PMC length: width ratio (i.e., PMCs were more elongated) for irregular tetrads than

Table 1

Difference in Pollen Mother Cell (PMC) Length: Width Ratio between Groups of Regular and Irregular Tetrads at the Species Level

\begin{tabular}{|c|c|c|c|c|c|}
\hline Plant species and tetrad group & Proportion & PMC ratio $(\mathrm{SE})$ & $n$ & $t$ & $P$ \\
\hline Albucca nelsonii & & & 60 & 5.48 & $<.0001$ \\
\hline Regular & .25 & $1.21(.14)$ & & & \\
\hline Irregular & .75 & $1.52(.30)$ & & & \\
\hline Beschorneria yuccoides & & & 30 & 2.60 & .017 \\
\hline Regular & .40 & $1.10(.08)$ & & & \\
\hline Irregular & .60 & $1.30(.31)$ & & & \\
\hline Hosta sp. & & & 60 & 1.11 & .27 \\
\hline Regular & .63 & $1.11(.10)$ & & & \\
\hline Irregular & .37 & $1.14(.10)$ & & & \\
\hline Convallaria maialis & & & 30 & .42 & .68 \\
\hline Regular & .80 & $1.11(.09)$ & & & \\
\hline Irregular & .20 & $1.13(.09)$ & & & \\
\hline Hypoxidia maheensis & & & 30 & .50 & .63 \\
\hline Regular & .83 & $1.02(.05)$ & & & \\
\hline Irregular & .17 & $1.03(.03)$ & & & \\
\hline Moraea aristata & & & 30 & 2.70 & .059 \\
\hline Regular & .87 & $1.05(.05)$ & & & \\
\hline Irregular & .13 & $1.13(.06)$ & & & \\
\hline Triteleia ixioides & & & 30 & $\ldots$ & $\ldots$ \\
\hline Regular & .90 & $1.09(.06)$ & & & \\
\hline Irregular & .10 & $1.16(.09)$ & & & \\
\hline Allium altaicum & & & 60 & $\ldots$ & $\ldots$ \\
\hline Regular & .93 & $1.04(.05)$ & & & \\
\hline Irregular & .07 & $1.06(.03)$ & & & \\
\hline Chlorophytum pauciflorum & & & 30 & $\ldots$ & $\ldots$ \\
\hline Regular & .93 & $1.06(.06)$ & & & \\
\hline Irregular & .07 & $1.24(.21)$ & & & \\
\hline Agapanthus umbellatus & & & 30 & $\ldots$ & $\ldots$ \\
\hline Regular & .97 & $1.08(.07)$ & & & \\
\hline Irregular & .03 & 1.03 (na) & & & \\
\hline
\end{tabular}

Note. Species are ordered by the observed proportion of irregular tetrads. Proportion of tetrads, group mean PMC length: width ratio, and sample size are indicated. In species where a $t$-test was possible, significant differences between groups are underlined, and a marginally significant difference is italicized. $\mathrm{na}=$ not available. 


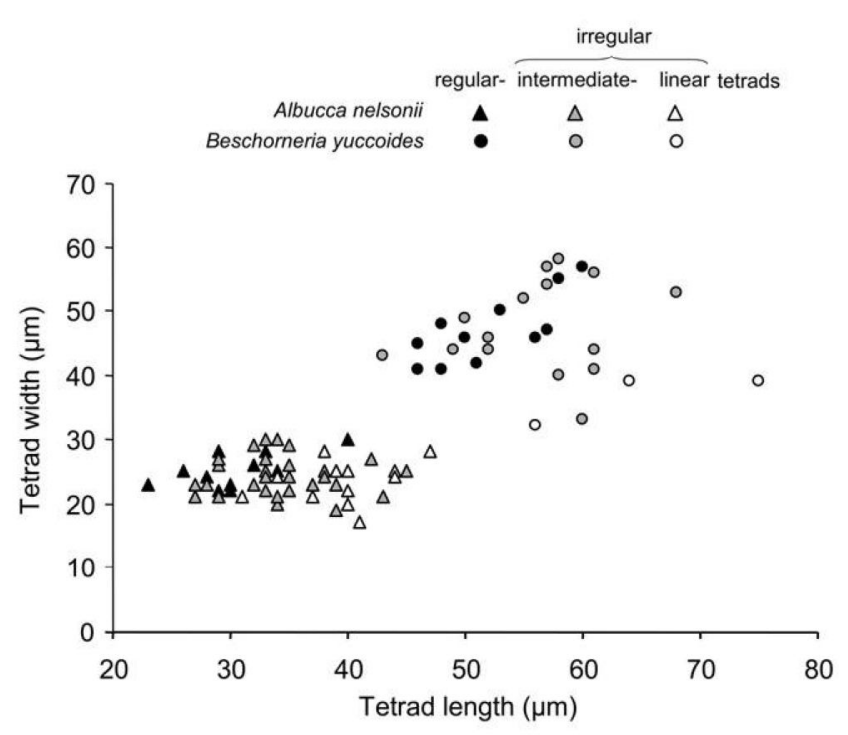

Fig. 3 Segregation of tetrad shape groups in relation to measured length and width of pollen mother cells for two species producing linear tetrads. Triangles = Albucca nelsonii; circles = Beschorneria yuccoides. For both species, black symbols represent regular tetrads, gray symbols represent intermediate tetrads, and white symbols represent linear tetrads.

for regular tetrads (table 1). This difference in mean PMC length: width ratio between tetrad groups was tested for the six species with more than $10 \%$ irregular tetrads and was statistically significant for $A$. nelsonii and B. yuccoides and marginally significant for Moraea aristata (table 1). With all species combined, the relationship between PMC shape and tetrad shape is highly significant ( $G=146.4, P<0.0001$; fig. 4).

\section{Discussion}

Our results show that premeiotic PMC shape has an impact on the following tetrad shapes during microspore development in Asparagales species with successive cytokinesis. Rounder PMCs usually translate into regular tetrad shapes (tetragonal, decussate), while more elongated PMCs tend to produce tetrads with less regular shapes such as linear or T-shaped tetrads (fig. 4; see also fig. 1.5). This pattern is general in our sample and is likely to be found in other monocots, a clade with a high frequency of species with successive cytokinesis (Rudall et al. 1997).

Cytokinesis type is already known to influence tetrad shape: tetrahedral (or more rarely rhomboidal) tetrads are usually produced when cytokinesis is simultaneous, whereas successive cytokinesis is associated with the production of tetragonal or decussate tetrads (Rudall et al. 1997). Here, I describe a novel factor involved in tetrad shape diversity: in species with successive cytokinesis, irregular tetrads seem to originate from elongated PMCs, while rounder PMCs yield mostly regular shapes (fig. 4). Irregular tetrads may thus not be teratological, as has been suggested in the literature but instead may be the result of variation in premeiotic PMC shape.
Whether the same pattern exists in species having simultaneous cytokinesis requires further study. Rhomboidal tetrads, for example, also seem to be produced by more elongated PMCs in species with simultaneous cytokinesis (L. Penet, personal observation).

Two of the study species (Albucca nelsonii and Beschorneria yuccoides) had PMC shapes that departed significantly from average PMC shapes in our sample (fig. 2). Given that these species belong to different families (Duvall et al. 1993), the increase in PMC shape diversity has arisen independently twice. Variation in PMC shape may have evolved because of selection, although this hypothesis remains unclear with regard to pollen morphology since all of the study species produce monosulcate pollen grains (Penet et al. 2007). PMC shape variation may also arise as a by-product of other processes, such as polyploidy or genome size (Ressayre et al. 2002). However, because DNA content is highly variable among our study species, one would have expected greater PMC shape diversity in our sample than was actually observed. Another nonexclusive hypothesis would take into account intraspecific sources of variation in PMC shape such as locular spatial constraints within anthers (fig. 1.6). Indeed, pollen number is correlated with stamen size (Ritland and Ritland 1989), and tetrad shape is known to vary along anthers (Wilson 1949), as well as with differences in microsporocyte shape (dan Dicko-Zafimahova 1980; Furness 2008). It would bc of intcrest to study PMC and tetrad shapc variation within anther locules, contrasting, for instance, closely related species with different stamen sizes or species with anther size polymorphisms.

Tetrad diversity is highly relevant in the study of microsporogenesis because it is associated with diversity of apertures in mature pollen grains, a feature that is under selective influence (Dajoz et al. 1991, 1993). Depending on how cell walls are formed during cytokinesis to separate microspores, different tetrad shapes generate different aperture patterns (Ressayre et al. 2002). In all of our study species, successive cytokinesis is as-

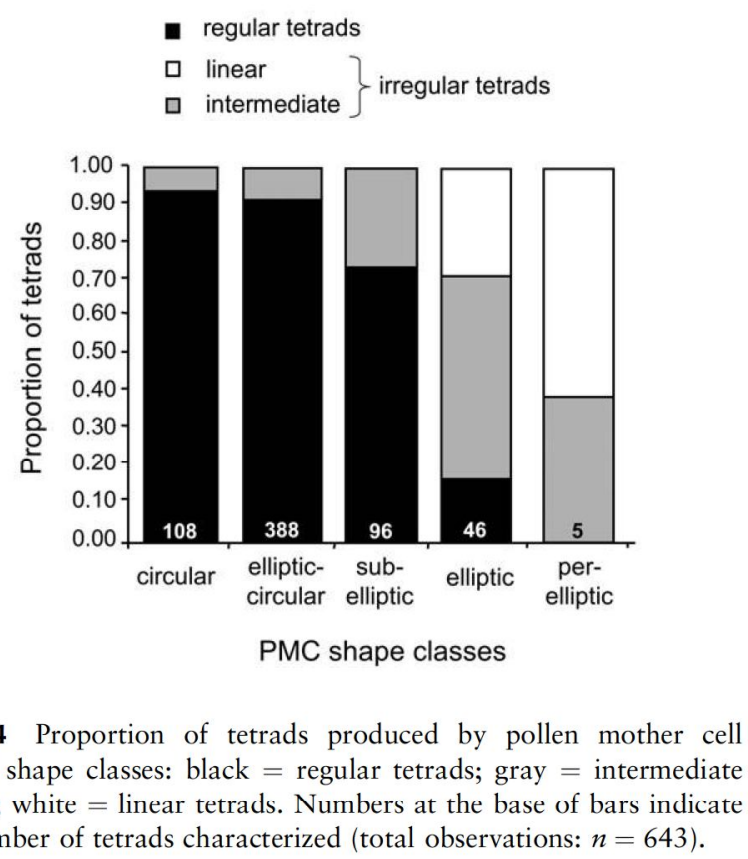


sociated with centrifugal cell division that forces pollen into monosulcate shape (Penet et al. 2007). Tetrad diversity therefore did not translate into pollen morphological differences, even in species producing frequent irregular tetrads (table 1). In those species, selection on tetrad shape may be relaxed, resulting in more developmental variation, as is observed for microsporogenesis in other species (Albert et al. 2009; Nunes et al. 2009). In contrast, such a diversity of tetrads would probably result in greater aperture diversity in species with simultaneous cytokinesis, unless alternative pollen morphologies are counterselected. This topic needs further exploration in species with simultaneous cytokinesis. In conclusion, PMC shape at the onset of meiosis impacts tetrad shapes produced after meiosis. Some species with successive cytokinesis have a greater PMC shape diversity and therefore greater tetrad diversity, and we still need to understand whether this diversity is selected for. Packaging constraints within locules in anthers is a promising hypothesis.

\section{Acknowledgments}

I am grateful to A. Forchioni, B. Albert, S. Nadot, and A. Ressayre for great discussions and help with technical aspects of staining and microscopy and to C. L. Collin and C. S. Tysor for helpful comments on early versions of the manuscript.

\section{Literature Cited}

Abramova LI, NA Avalkina, EA Golubeva, ZS Pyzhenkova, IN Golubovskaya 2003 Synthesis and deposition of callose in anthers and ovules of meiotic mutants of maize (Zea mays). Russ J Plant Physiol 50:324-329.

Albert B, P-H Gouyon, A Ressayre 2009 Microsporogenesis variation in Codiaeum producing inaperturate pollen grain. C R Biol 332:507-516.

Albert B, S Nadot, L Dreyer, A Ressayre 2010 The influence of tetrad shape and intersporal callose wall formation on pollen aperture pattern ontogeny in two eudicot species. Ann Bot 106:557-564.

Albert B, C Raquin, M Prigent, S Nadot, F Brisset, M Yang, A Ressayre 2011a Successive microsporogenesis affects pollen aperture pattern in the tam mutant of Arabidopsis thaliana. Ann Bot 107:1421-1426.

Albert B, A Ressayre, S Nadot $2011 b$ Correlation between pollen aperture pattern and callose deposition in late tetrad stage in three species producing atypical pollen grains. Am J Bot 98:189-196.

Angiosperm Phylogeny Group 1998 An ordinal classification for the families of flowering plants. Ann Mo Bot Gard 85:531-553.

__ 2003 An update of the Angiosperm Phylogeny Group classification for the orders and families of flowering plants: APG II. Bot J Linn Soc 141:399-436.

Angold RE 1967 The ontogeny and fine structure of the pollen grain of Endymion non-scriptus. Rev Palaeobot Palynol 3:205-212.

Blackmore S 2007 Pollen and spores: microscopic keys to understanding the earth's biodiversity. Plant Syst Evol 263:3-12.

Brewbaker JL 1967 The distribution and phylogenetic significance of binucleate and trinucleate pollen grains in the angiosperms. Am J Bot 54:1069-1083.

Caddick L, CA Furness, KL Stobart, PJ Rudall 1998 Microsporogenesis and pollen morphology in Dioscoreales and allied taxa. Grana 37:321-336.

Copenhaver GP 2005 A compendium of plant species producing pollen tetrads. J NC Acad Sci 121:17-35.

Dajoz I, I Till-Bottraud, P-H Gouyon 1991 Evolution of pollen morphology. Science 253:66-68.

__ 1993 Pollen aperture polymorphism and gametophyte performance in Viola diversifolia. Evolution 47:1080-1093.

dan Dicko-Zafimahova L 1980 Etude ontogénique de la pollinie de Calotropis procera (Asclepiadaceae): apport de la microscopie photonique. Grana 19:85-98.

Duvall MR, MT Clegg, MW Chase, WD Clark, WJ Kress, HG Hills, LE Eguiarte, et al 1993 Phylogenetic hypotheses for the monocotyledons constructed from rbcL sequence data. Ann Mo Bot Gard 80:607-619.

Furness CA 2008 Successive microsporogenesis in eudicots, with particular reference to Berberidaceae (Ranunculales). Plant Syst Evol 273:211-223.
Furness CA, PJ Rudall 1999 Microsporogenesis in monocotyledons. Ann Bot 84:475-499.

2001 Pollen and anther characters in monocot systematics. Grana 40:17-25.

2004 Pollen aperture evolution - a crucial factor for eudicot success? Trends Plant Sci 9:154-158.

Furness CA, PJ Rudall, FB Sampson 2002 Evolution of microsporogenesis in angiosperms. Int J Plant Sci 163:235-260.

Ghimire B, BK Ghimire, K Heo 2011 Microsporogenesis in Rauvolfia serpentina (L.) Benth ex Kurz (Apocynaceae): an evidence for dual cytokinesis in microspore mother cells. J Med Plant Res 5: 432-438.

Grossniklaus U 2011 Plant germline development: a tale of crosstalk signaling and cellular interactions. Sex Plant Reprod 24: 91-95.

Harlcy MM, J Dransficld 2003 Triporate pollen in the Arccaccac. Grana 42:3-19.

Hesse M 2000 Pollen wall stratification and pollination. Plant Syst Evol 222:1-17.

Ma H, V Sundaresan 2010 Development of flowering plant gametophytes. Pages 379-412 in MCP Timmermans, ed. Plant development. Academic Press, San Diego, CA.

Nadot S, A Forchioni, L Penet, J Sannier, A Ressayre 2006 Links between early pollen development and aperture pattern in monocots. Protoplasma 228:55-64.

Nadot S, CA Furness, J Sannier, L Penet, S Triki-Teurtroy, B Albert, A Ressayre 2008 Phylogenetic comparative analysis of microsporogenesis in angiosperms with a focus on monocots. Am J Bot 95: 1426-1436.

Nunes EL, C Bona, MC Moço, AI Coan 2009 Release of developmental constraints on tetrad shape is confirmed in inaperturate pollen of Potamogeton. Ann Bot 104:1011-1015.

Penet L, M Laurin, P-H Gouyon, S Nadot 2007 Constraints and selection: insights from microsporogenesis in Asparagales. Evol Dev 9:460-471.

Penet L, S Nadot, A Ressayre, A Forchioni, L Dreyer, P-H Gouyon 200.5 Multiple developmental pathways leading to a single morph: monosulcate pollen (examples from the Asparagales). Ann Bot 95:331-343.

Rangaswamy NS, J Subramanyan, R Tandon, SR Bhuskute 2001 Microspore tetrad analysis: can either type of microsporogenesis engender tetrads of all configurations? Phytomorphology 51: 573-586.

R Development Core Team 2011 R: a language and environment for statistical computing. R Foundation for Statistical Computing, Vienna.

Ressayre A, L Dreyer, S Triki-Teurtroy, A Forchioni, S Nadot 2005 Post-meiotic cytokinesis and pollen aperture pattern ontogeny: 
comparison of development in four species differing in aperture pattern. Am J Bot 92:576-583.

Ressayre A, B Godelle, C Raquin, P-H Gouyon 2002 Aperture pattern ontogeny in angiosperms. J Exp Zool 294:122-135.

Ritland C, K Ritland 1989 Variation of sex allocation among eight taxa of the Mimulus guttatus species complex (Scrophulariaceae). Am J Bot 76:1731-1739.

Rudall PJ, CA Furness, MW Chase, MF Fay 1997 Microsporogenesis and pollen sulcus type in Asparagales (Lilianae). Can J Bot 75:408-430.

Sampson FB 1969 Cytokinesis in pollen mother cells of angiosperms with emphasis on Laurelia novae-zelandie (Monimiaceae). Cytologia 34:627-633.

Sannier J, W Baker, M-C Anstett, S Nadot 2009 A comparative analysis of pollinator type and pollen ornamentation in the Araceae and the Arecaceae, two unrelated families of the monocots. BMC Res Notes 2:145.

Wilson GB 1949 Cytological studies in the Musae. IV. Tetrad shapes. Trans Am Microsc Soc 68:217-221.

Wilson ZA, D-B Zhang 2009 From Arabidopsis to rice: pathways in pollen development. J Exp Bot 60:1479-1492. 